\title{
Medical versus surgical termination of early pregnancy: satisfaction with care, emotional impact and acceptability of the procedure
}

\section{Prasanna L. Akkenapally*, Vasundhara Kamineni}

Department of Obstetrics and Gynaecology, Kamineni Academy of Medical Sciences and Research Centre Hyderabad, Telangana, India

Received: 19 July 2016

Accepted: 11 August 2016

\section{*Correspondence:}

Dr. Prasanna L. Akkenapally,

E-mail: drlatasri@gmail.com

Copyright: (C) the author(s), publisher and licensee Medip Academy. This is an open-access article distributed under the terms of the Creative Commons Attribution Non-Commercial License, which permits unrestricted non-commercial use, distribution, and reproduction in any medium, provided the original work is properly cited.

\section{ABSTRACT}

Background: Aim of the study was to compare the satisfaction with care and acceptability of the procedure next time between medical and surgical termination of pregnancy (TOP) and the factors affecting it.

Methods: This is a prospective observational study conducted at Jyothi Maternity Centre, a project of population health services of India (PHSI). Total 213 women were included in the study, of these 108 women received medical termination of pregnancy (MTOP) and 105 received surgical termination of pregnancy (STOP). Questionnaires regarding satisfaction with care, experience of care, psychological rating scales and acceptability were given at the follow- up visit at two weeks. The data was collected and computed for statistical analysis.

Results: Women in both the groups were similar with respect to age, marital status, socioeconomic status, educational status and parity. The mean age was 24 years. The success rate with STOP (100\%) was more than MTOP (79.6\%), with $\mathrm{p}$-value of 0.001 . The experience of care comparing the semantic variables showed MTOP to be less painful and safer, while STOP was good and faster. The total mean impact scores and depression scores of MTOP were higher than STOP and it was statistically significant with p- values of 0.010 and $<0.001$ respectively. The acceptability rate with MTOP was $79.6 \%$ and with STOP $95.2 \%$.

Conclusions: Satisfaction with both the methods of medical and surgical abortion is high. Acceptability of the procedure next time was more with surgical abortion. MTOP had higher emotional impact.

Keywords: Early abortion, Psychological impact, Preference

\section{INTRODUCTION}

Abortion is a health issue which is fraught with controversy, conflict and condemnation. One reason that abortion evokes strong emotions and reactions is that it reflects women's need to control their own bodies, a human rights principle that contravenes dominant patriarchal attitudes and practices and, in some cases, cultural beliefs. ${ }^{1}$

In 2012, World Health Organization (WHO) and the Guttmacher Institute reported that $56 \%$ of abortions in developing countries were unsafe. ${ }^{2}$ Increasing access to safe abortion services is the most effective way of preventing the burden of unsafe abortion, which is achieved by increasing safe choices for pregnancy termination.

In December 2008, Mifepristone + Misoprostol (200 mg $1 \mathrm{tab}+4$ tab $200 \mathrm{mcg}$ each) combi pack was approved by the Central Drugs Standard Control Organization, Directorate General of Health Services for medical termination of intrauterine pregnancy for up to 63 days of gestation. Regimens that use low doses of mifepristone (200 mg) have similar efficacy and lower costs compared with those that use mifepristone at $600 \mathrm{mg} .{ }^{3}$ Buccal and 
sublingual misoprostol can be administered as early as 24 hours after mifepristone administration with higher efficacy. ${ }^{4-6}$ Gastrointestinal adverse effects are common with mifepristone and misoprostol. Sublingual misoprostol is associated with a higher rate of chills. ${ }^{7}$ Excessive bleeding is one of the complications, which may need emergency care based on baseline hemoglobin levels and amount of bleeding, less than $1 \%$ of women will need emergency curettage because of excessive bleeding. ${ }^{6}$ In most studies of medical abortion of gestation up to 63 days with mifepristone followed by misoprostol, less than $5 \%$ of patients undergo surgical evacuation. $^{8}$

Features of medical abortion: ${ }^{6}$

- Usually avoids invasive procedure

- Usually avoids anesthesia

- Days to weeks to complete

- Available during early pregnancy

- High success rate (approximately 95\%)

- Bleeding commonly not perceived as light

- Requires follow up to ensure completion of abortion

- Patient participation throughout a multi-step process.

Manual vacuum aspiration (MVA) is safe, cost effective and outpatient procedure for early abortion. The World Health Organization (WHO) recommends MVA as a preferred method for uterine evacuation for induced abortion in early pregnancy. ${ }^{9}$ MVA is done with MVA aspirator syringe and cannula. A no touch technique is followed. Prior to the procedure $400 \mathrm{mcg}$ of misoprostol is kept per vagina, for cervical ripening and dilatation, analgesics like ibuprofen can be given. Para-cervical block is given with $10 \mathrm{ml}$ of $1 \%$ lidocaine $(100 \mathrm{mg})$. Addition of music to ibuprofen and Para cervical block seemed to increase pain scores. ${ }^{10}$ For examining the tissue, the contents of the collection bottle or syringe are emptied in to a strainer and after rinsing, the specimen is placed into a glass flat-bottom pan with backlighting and tap water or saline is added to float the specimen. Chorionic villi, embryonic membranes (gestational sac) and fetal parts are distinguished from decidua. As the tissue examination is done immediately after the procedure, the chances of incomplete abortion are rare.

Features of surgical abortion: ${ }^{6}$

- Involves invasive procedure

- Allows use of sedation if desired

- Complete in a predictable period of time

- Available during early pregnancy

- High success rate (99\%)

- Bleeding commonly perceived as light

- Does not require follow up in most cases

- Patient participation in a single-step process

Women may like certain methods for reasons related to emotional associations with a particular method, time required for completion, similarity (or not) to miscarriage or menstruation, ability to keep the procedure private, amount of pain involved, and amount of time lost from work. The introduction of the medical abortion procedure is not only a matter of saving lives, but rather a privilege of preference for one of two procedures. When comparing medical and surgical abortion, focus should therefore not only on efficacy and complications, but also on acceptability and patient satisfaction.

\section{METHODS}

The present study was conducted among women with gestational age (GA) $<63$ days, referred to Jyothi Maternity Centre for early termination of pregnancy from March 2013 to June 2014. The study design was prospective observational study and it was approved by the local ethics committee. A trans-vaginal ultrasound was performed to confirm the gestational age. The inclusion criteria were age more than 18 years, GA $<63$ days from their last menstrual period, singleton intrauterine pregnancy, lived within 1 hour distance of the hospital, a legal indication for termination with informed consent and willing to follow the study protocol and follow up with written consent. The exclusion criteria were missed abortion, multiple pregnancies, medical or surgical contraindications, on anticoagulant therapy, hemoglobin less than $10 \mathrm{~g} / \mathrm{dL}$ and known or suspected pelvic infection.

A detailed history regarding the last menstrual period, menstrual cycles, past obstetric history, past history of method of abortion, past medical and surgical history, allergy to drugs and treatment history was obtained. A general and physical examination was done. Pelvic examination was done to exclude pelvic infection and assess the size of the uterus. Routine investigations to assess the hemoglobin status, blood grouping and $\mathrm{Rh}$ isoimmunization, trans-vaginal ultrasonography (TVS) for exact GA was done. The women were informed about the study protocol and follow up after 2 weeks and a written consent obtained.

Women were explained in detail about medical method and manual vacuum aspiration (MVA) and were allotted at random into either groups. Total 250 women were selected for the study, out of this 15 women opted out of the study, 22 lost follow-up, so only 213 women were included in the study. Out of this 108 women received medical method and 105 received surgical method.

In our study for medical termination of pregnancy (MTOP) $200 \mathrm{mg}$ of oral mifepristone was given under supervision followed by sublingual misoprostol $800 \mathrm{mcg}$ after 24 hours, in two doses of 400 mcg each 6 hours apart, to be taken at home. Women are counselled that the bleeding is much heavier than menses and potentially with severe cramping, women are advised to take analgesics like mefenamic acid $500 \mathrm{mg}$ thrice daily if cramping is severe. Adverse effects like nausea, 
vomiting, diarrhea, head ache, dizziness, and chills are recorded and symptomatic treatment given where ever required. The women are explained about the follow up visit after one week, an ultrasound examination is performed, women with persistent gestational sac or with retained products of conception are given another dose of misoprostol, and followed after another week with TVS, if still products of conception remain, and surgical evacuation is recommended and performed. These cases were considered as failure. Women in the surgical termination of pregnancy (STOP) group underwent manual vacuum aspiration (MVA) with local anesthesia, tissue examined for gestational sac. ${ }^{11}$ If the woman became too anxious and failed to cooperate, general anesthesia was given. Follow up visit was scheduled after 2 weeks, at which both the groups received a questionnaire, data collected and computed.

The questionnaire for satisfaction with care consisted of quality of care, counseling and support after the procedure using a 5- point Likert scale (from excellent to poor). ${ }^{12}$ To assess the experience of care, semantic differential rating with twelve bipolar objectives were used scored along a positive or negative attitude ranging from +3 to -3 . $^{13,14}$ Distress was measured using the impact of event scale (IES) at 2 weeks. This 15 - item scale, with sub scales for intrusion and avoidance, measures subjective distress to a specific event (TOP). ${ }^{15}$ Anxiety and depression were measured using hospital anxiety and depression scale (HADS) at 2 weeks. This is a widely used 14 - item self - report scale designed for medical patients. ${ }^{16}$ Pain was measured on 0 to 10 numeric pain rating scale. Amount of bleeding assessed as excessive, heavy, moderate and minimal. Acceptability of the procedure after 2 weeks of termination was measured as the percentage that would opt for the same procedure again.

Statistical analysis was performed with SPSS Inc., Chicago IL. In order to test for the outcome variables the mean values of both the groups were compared to compute the difference and analyzed with an Independent sample $T$ test to assess for statistical differences and the $p$ - value was calculated, confidence interval and odds ratio were computed and interpreted. Distribution of participants according to the satisfaction among both groups were computed and analyzed with Pearson's Chi square test to assess for association of method of termination to satisfaction of the patient.

\section{RESULTS}

Total 213 women participated in our study, of which 108 women received MTOP and 105 received STOP. Baseline characteristics (Table 1) were similar in both the group like the mean age, parity and history of previous TOP except the gestational age in which the number of women with gestational age $>49$ days in MTOP was more than STOP. The success rate (Table 2) in MTOP was $79.6 \%$ and in STOP $100 \%$, the difference is statistically significant $(\mathrm{p}$ value $=0.001)$.

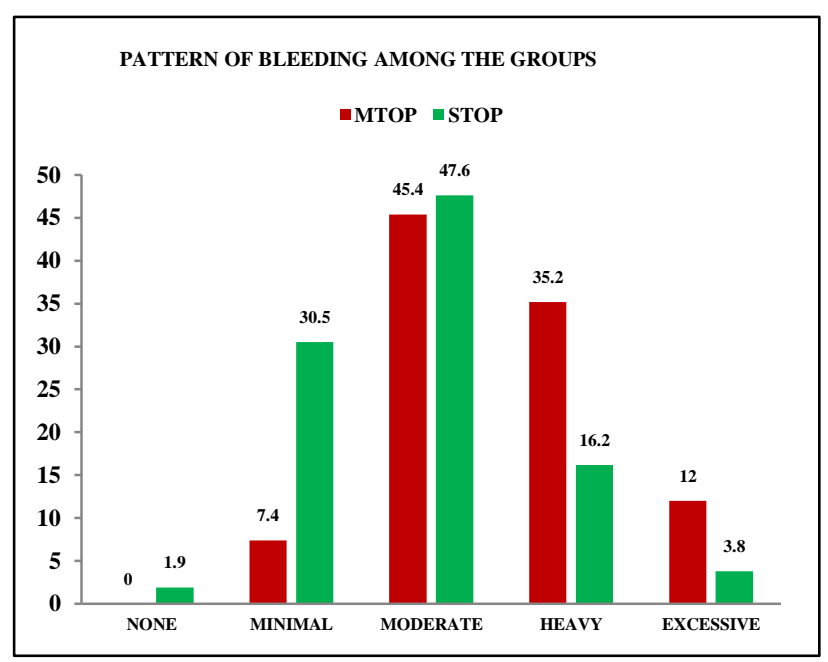

Figure 1: Comparison of bleeding 2 weeks after discharge.

Table 1: Characteristics of TOP.

\begin{tabular}{|llllll|}
\hline Age & Mean \pm SD & $25 \pm 5.82$ & & \multicolumn{2}{l|}{ STOP } \\
& & Frequency & Percent \% & Frequency & Percent \% \\
\hline Parity & & & & & \\
\hline & Primi & 48 & 44.4 & 51 & 48.6 \\
\hline & Multi & 60 & 55.6 & 54 & 51.4 \\
\hline & Total & $\mathbf{1 0 8}$ & $\mathbf{1 0 0 . 0}$ & $\mathbf{1 0 5}$ & $\mathbf{1 0 0 . 0}$ \\
\hline Gestational age & & & & & \\
\hline & $<49$ days & 34 & 31.5 & 53 & 50.5 \\
\hline & $>49$ days & 74 & 68.5 & 52 & $\mathbf{1 0 0 . 0}$ \\
\hline & Total & $\mathbf{1 0 8}$ & $\mathbf{1 0 0 . 0}$ & $\mathbf{1 0 5}$ & 22.85 \\
\hline & & & & & 77.15 \\
\hline
\end{tabular}


The amount of bleeding experienced (Figure 1) was moderate to excessive in MTOP and minimal to heavy in
STOP. The mean pain scores (Table 3) in MTOP group showed lower values compared to STOP but the difference is not statistically significant $(\mathrm{p}=0.094)$.

Table 2: Bleeding as reported at 2 weeks follow-up and success rate.

\begin{tabular}{|c|c|c|c|c|c|}
\hline & & \multicolumn{2}{|l|}{ MTOP } & \multicolumn{2}{|l|}{ STOP } \\
\hline & & Frequency & Percent \% & Frequency & Percent \% \\
\hline \multicolumn{6}{|l|}{ Bleeding } \\
\hline None & & 0 & 0 & 2 & 1.9 \\
\hline Minimal & & 8 & 7.4 & 32 & 30.5 \\
\hline Moderate & & 49 & 45.4 & 50 & 47.6 \\
\hline Heavy & & 38 & 35.2 & 17 & 16.2 \\
\hline Excessive & & 13 & 12.0 & 4 & 3.8 \\
\hline Total & & 108 & 100.0 & 105 & 100.0 \\
\hline \multirow[t]{2}{*}{ Success rate ${ }^{*}$} & Not successful & 22 & 20.4 & 0 & 0 \\
\hline & Successful & 86 & 79.6 & 105 & 100 \\
\hline
\end{tabular}

$*=$ p-value 0.001

Table 3: Comparison of mean pain scale ratings among participants of the two groups.

\begin{tabular}{|llllll|}
\hline & Group & N & Mean & Std. deviation & $T$ \\
\multirow{2}{*}{ Pain-scale } & MTOP & 108 & 5.4815 & 1.68269 & $\mathrm{t}=1.678$ \\
\cline { 2 - 7 } & STOP & 105 & 5.8381 & 1.40140 & $\mathrm{p}=0.094$ \\
\hline
\end{tabular}

Table 4: Comparison of Satisfaction with the treatment between methods of pregnancy termination.

\begin{tabular}{|c|c|c|c|c|c|c|c|c|}
\hline & & \multicolumn{5}{|c|}{ Satisfaction } & \multirow{2}{*}{ Total } & \multirow{2}{*}{ Chi-Square test } \\
\hline & & Poor & Fair & Good & Very good & Excellent & & \\
\hline \multirow{4}{*}{ Group } & \multirow{2}{*}{ MTOP } & 2 & 7 & 52 & 41 & 6 & 108 & \multirow{6}{*}{$\begin{array}{l}\chi^{2}=3.771 \\
p=0.438\end{array}$} \\
\hline & & $1.9 \%$ & $6.5 \%$ & $48.1 \%$ & $38.0 \%$ & $5.6 \%$ & $100.0 \%$ & \\
\hline & \multirow{2}{*}{ STOP } & 0 & 10 & 57 & 34 & 4 & 105 & \\
\hline & & $0.0 \%$ & $9.5 \%$ & $54.3 \%$ & $32.4 \%$ & $3.8 \%$ & $100.0 \%$ & \\
\hline \multirow{2}{*}{ Total } & & 2 & 17 & 109 & 75 & 10 & 213 & \\
\hline & & $0.9 \%$ & $8.0 \%$ & $51.2 \%$ & $35.2 \%$ & $4.7 \%$ & $100.0 \%$ & \\
\hline
\end{tabular}

Table 5: comparison of mean semantic variables differential scores between two groups after 2 weeks of termination.

\begin{tabular}{|c|c|c|c|c|c|}
\hline \multirow[t]{2}{*}{ Semantic variable $(-3$ to +3$)$} & \multicolumn{2}{|c|}{ MTOP $(\mathbf{N}=108)$} & \multicolumn{2}{|c|}{$\operatorname{STOP}(\mathbf{N}=105)$} & \multirow[t]{2}{*}{ P value } \\
\hline & Mean & SD & Mean & SD & \\
\hline Painful to painless & -0.8241 & 0.86282 & -1.1714 & 0.56257 & 0.001 \\
\hline Sad to happy & -0.7315 & 0.80427 & -0.9714 & 0.80213 & 0.03 \\
\hline Bad to good & -0.2407 & 1.02191 & -0.7143 & 0.64621 & $<0.001$ \\
\hline Unpleasant to pleasant & -1.0185 & 0.51121 & -0.4190 & 0.51480 & $<0.001$ \\
\hline Negative to positive & -0.3611 & 0.58738 & -0.0381 & 0.19234 & $<0.001$ \\
\hline Dangerous to safe & 0.7407 & 1.02648 & -0.6000 & 0.49225 & $<0.001$ \\
\hline Unattractive to attractive & 0.6481 & 0.88934 & -0.7810 & 0.43811 & $<0.001$ \\
\hline Harsh to mild & 0.8796 & 0.60709 & -0.8762 & 0.40892 & $<0.001$ \\
\hline Disagreeable to agreeable & 0.6481 & 0.56889 & -0.9810 & 0.13735 & $<0.001$ \\
\hline Passive to active & -1.8796 & 0.37981 & 0.9714 & 0.57941 & $<0.001$ \\
\hline Hard to easy & -0.7222 & 0.96512 & -1.1333 & 0.91006 & 0.002 \\
\hline Slow to fast & -2.4537 & 0.68882 & 1.4667 & 0.53828 & $<0.001$ \\
\hline
\end{tabular}

SD - standard deviation. 
Table 6: Comparison of mean score on psychological rating scale between two groups 2 weeks after termination.

\begin{tabular}{|llllll|}
\hline Psychological rating scale & MTOP $(\mathbf{N}=108)$ & \multicolumn{2}{l|}{ STOP $(\mathbf{N}=105)$} & p-value \\
\hline IES intrusive & Mean & SD & Mean & SD & \\
\hline IES avoidance & 7.6667 & 4.39201 & 6.9810 & 3.66108 & 0.217 \\
\hline IES total & 13.2500 & 4.10863 & 11.5333 & 2.83544 & $<0.001$ \\
\hline HAD anxiety & 20.9167 & 7.41068 & 18.5143 & 5.98574 & 0.010 \\
\hline HAD depression & 6.2407 & 2.643 & 4.6667 & 2.694 & $<0.001$ \\
\hline
\end{tabular}

IES = impact of event scale; $\mathrm{HAD}=$ hospital anxiety and depression scale; $\mathrm{SD}=$ standard deviation.

Table 7: Acceptability of the procedure at 2 weeks after termination.

\begin{tabular}{|llllll|}
\hline & & MTOP & & STOP & \\
\hline & & Frequency & Percent \% & Frequency & Percent \% \\
\hline Acceptability & & & & & \\
\hline & NO & 22 & 20.4 & 5 & 4.8 \\
\hline & YES & 86 & 79.6 & 100 & 95.2 \\
\hline & Total & $\mathbf{1 0 8}$ & $\mathbf{1 0 0 . 0}$ & $\mathbf{1 0 5}$ & $\mathbf{1 0 0 . 0}$ \\
\hline
\end{tabular}

Figure 2 showing Comparison of semantic variables between MTOP and STOP.

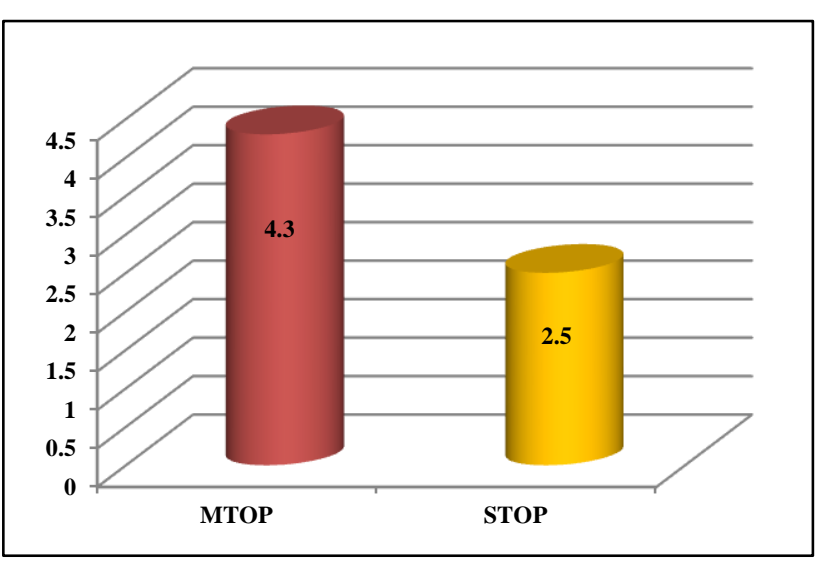

Figure 2: (a) Pain perception.

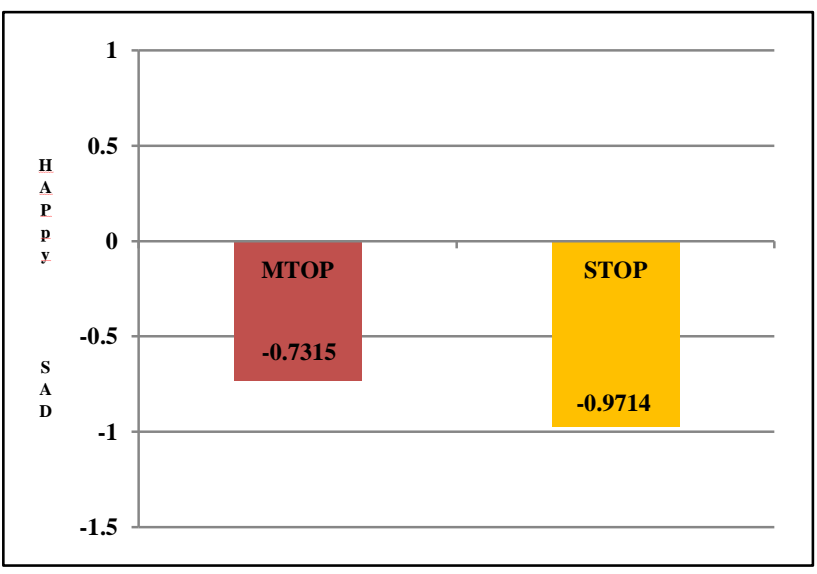

Figure 2: (b) Happiness score.

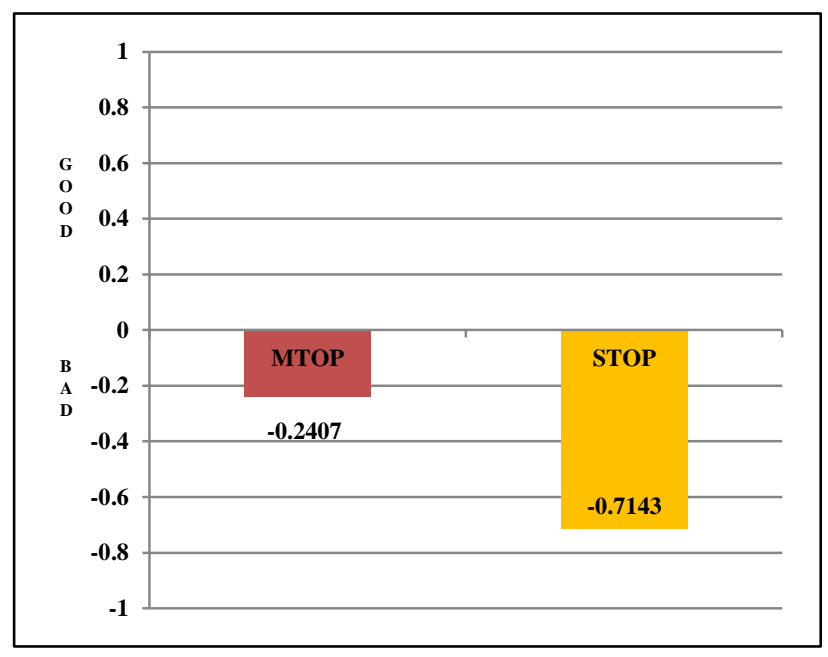

Figure 2: (c) Opinion on type of termination.

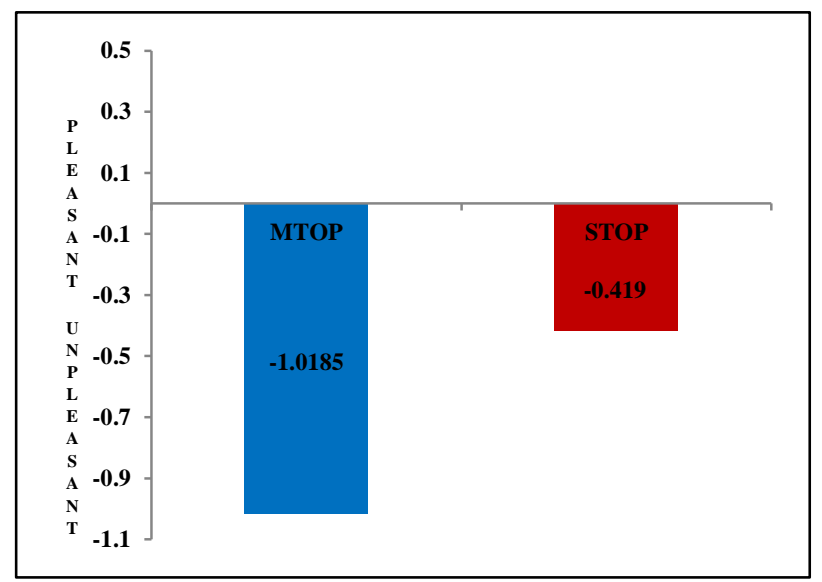

Figure 2: (d) Experience of type of termination. 


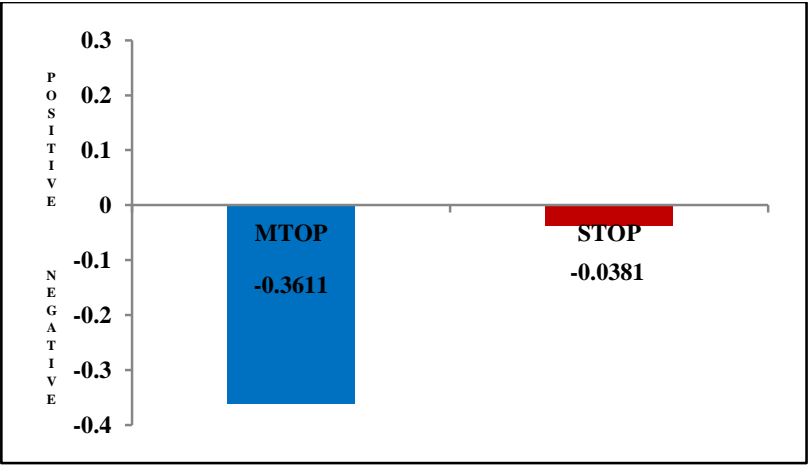

Figure 2: (e) Impact of type of termination.

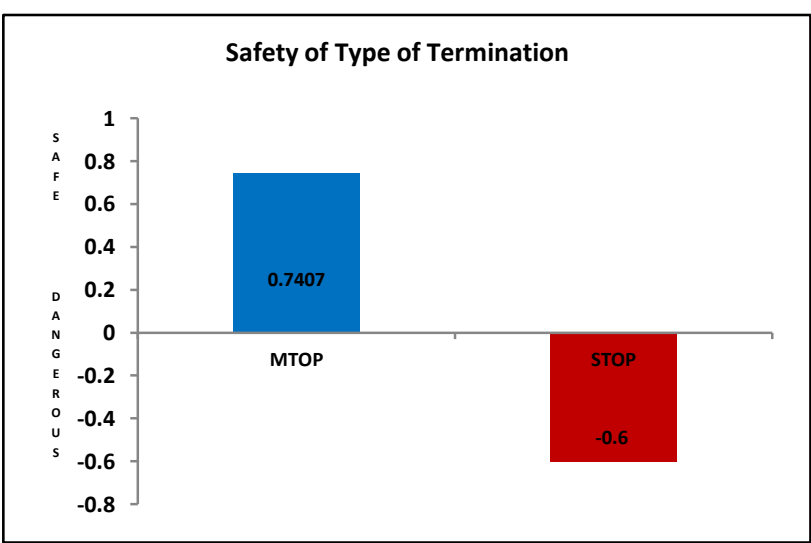

Figure 2: (f) Safety of type of termination.

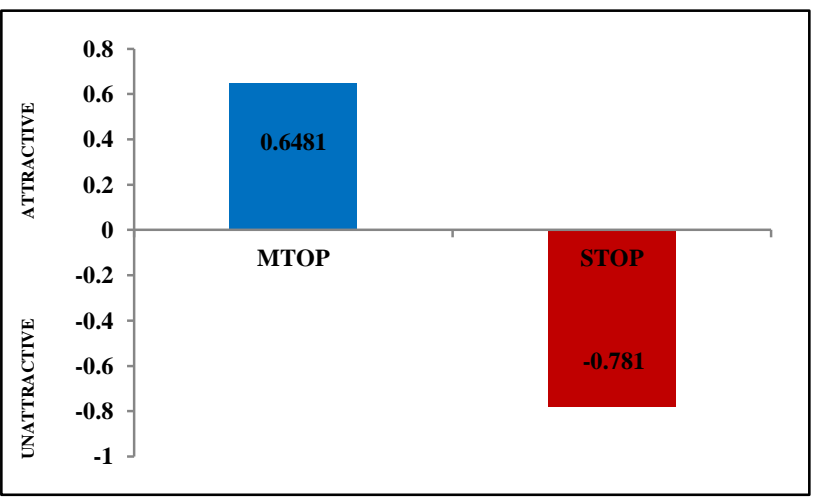

Figure 2: (g) Attractiveness of type of termination.

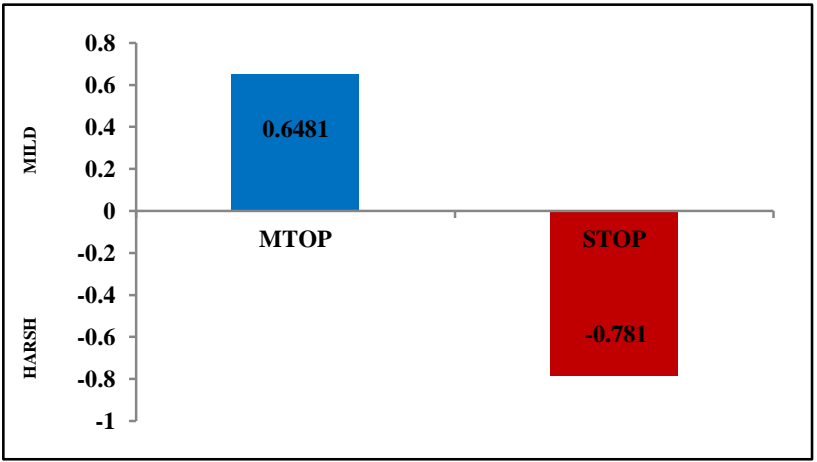

Figure 2: (h) Mildness of Type of Termination.

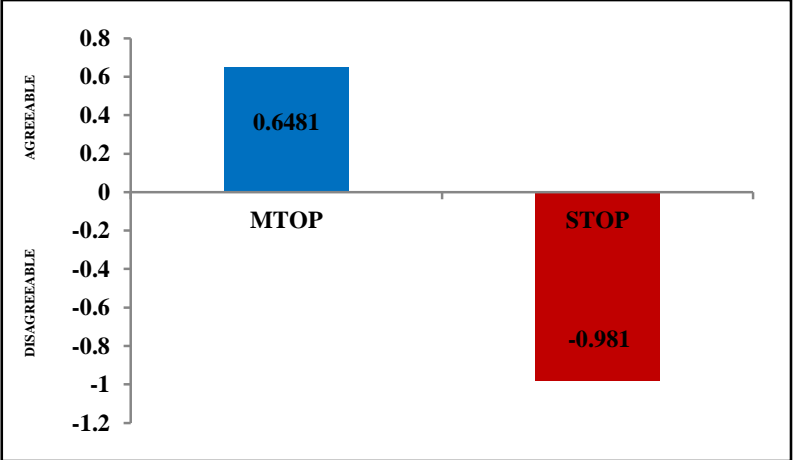

Figure 2: (i) Agreement of type of termination.

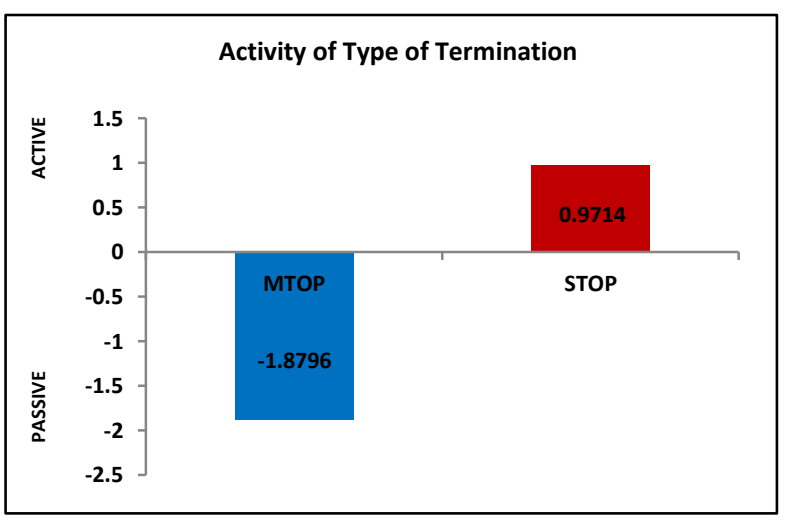

Figure 2: (j) Activity of type of termination.

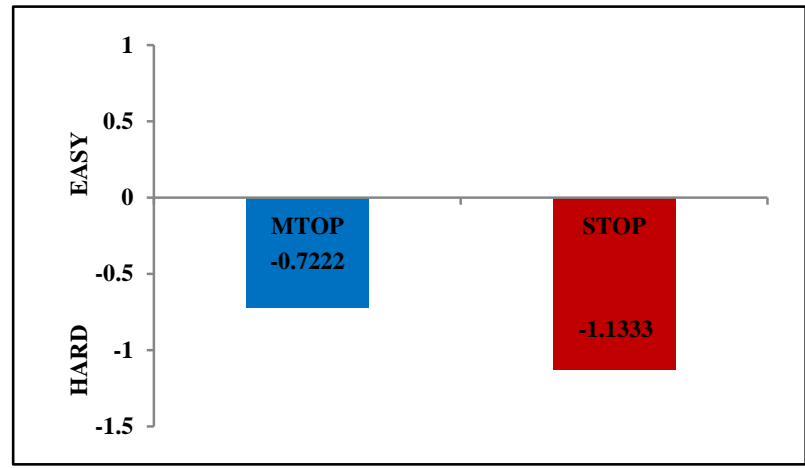

Figure 2: (k) Ease of type of termination.

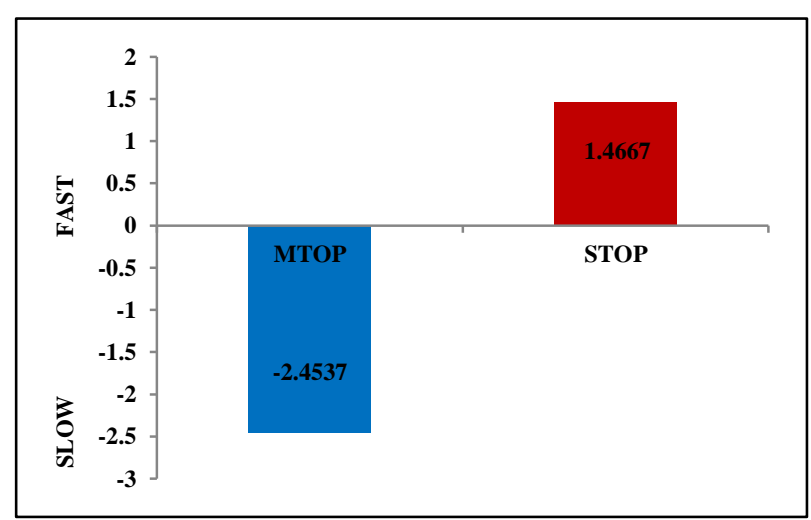

Figure 2: (l) Time takes for termination. 


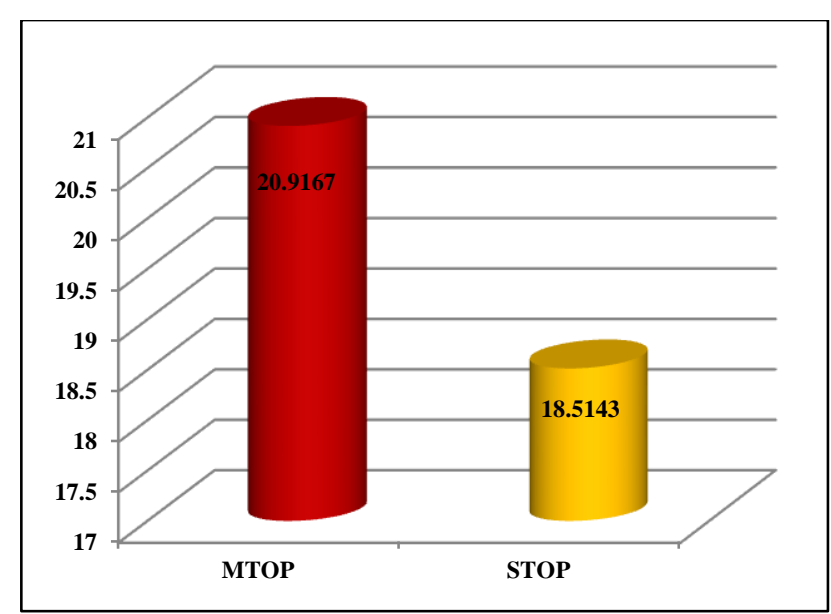

Figure 3: Comparison of mean total impact score.

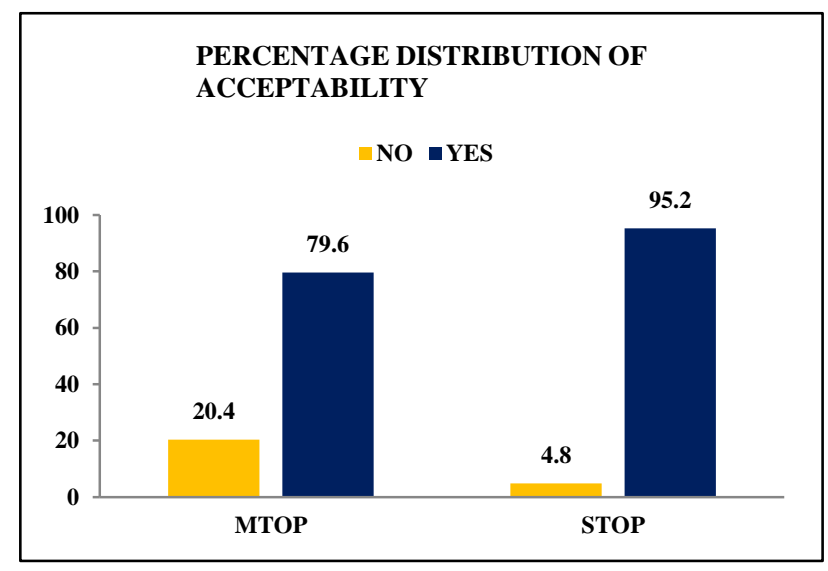

Figure 4: Acceptability of the procedure 2 weeks after termination

The satisfaction with care (Table 4) was good and very good in both the groups $(\mathrm{p}=0.438)$. The experience of care is shown in Table 5 with the comparison of semantic variables differential scores, MTOP is less painful compared to STOP $(\mathrm{p}=0.001)$. Happiness score was more in STOP group; but the experience was bad. MTOP group had unpleasant experience with a negative impact. MTOP was found to be safer, more attractive, milder, more agreeable, passive and easy compared to STOP. STOP was found to be faster than MTOP (Figure $2 \mathrm{a}, \mathrm{b}$, c, d, e, f, g, h, i, j, k, l). Table 6 compares the psychological rating scales to show the emotional impact of TOP. According to the IES scores all women fall in mild affected stage. ${ }^{15}$ The mean Impact of Event score (IES) intrusive score among MTOP group showed higher values compared to STOP, but it was not statistically significant ( $\mathrm{p}=0.217)$. But the mean IES avoidance scores in MTOP group showed higher values compared to STOP with significant statistical difference ( $\mathrm{p}$ - value $<0.001)$. The mean total IES score in MTOP group was higher than STOP group and it is statistically significant $(\mathrm{p}=0.010)$ (Figure 3$)$. The mean hospital anxiety scores in MTOP group showed higher values compared to STOP group ( $\mathrm{p}$-value of $<0.001$ ). Mean depression scores in
MTOP group was higher than STOP group and it is statistically significant with $\mathrm{p}$-value $<0.001$. According to HADS scores women in both groups are mildly affected. As far as acceptability of the procedure (Table 7) was concerned $95.2 \%$ of women in STOP group agreed to choose the procedure again whereas only $79.6 \%$ chose MTOP again (Figure 4).

\section{DISCUSSION}

The experience of medical evacuation of uterus compared with surgical evacuation is different enough to generate much interest and discussion. In our study the number of women in both the groups is almost equal. The success rate with MTOP was $79.6 \%$ and with STOP $100 \%$. This is consistent with the study done by Mary R et al showed $84 \%$ success in medical group and $97 \%$ in surgical group. ${ }^{17}$ The mean pain score was $5.48 \pm 1.68$ in MTOP and $5.83 \pm 1.40$ in STOP similar to that shown by Justine $\mathrm{Wu} \mathrm{P}$ et al they reported a mean pain score for the index abortion of $5.48 \pm 2.74 .^{18}$

The satisfaction rate when good, very good and excellent rates are added was $91.7 \%$ in MTOP and $90.5 \%$ in STOP. Woldetsadik et al reported satisfaction rates of $91.2 \%$ with medical abortion and $82 \%$ with MVA, Rodriguez. M, et al reported $84 \%$ with MTOP and $96 \%$ with STOP and Justine $\mathrm{P}$ et al reported $93 \%$ satisfaction rates. ${ }^{18-20}$

When the semantic variables are taken into consideration MTOP is safe, easy and milder whereas STOP is faster and complete, which explains the reason why some women favor medical abortion, because they perceive it to be more natural, want to avoid surgery or value the privacy of home environment while other women prefer surgical abortion because of the comfort and finality of the procedure being completed in a single clinical visit and their desire not see the fetus.

Anne et al reported that in induced abortion IES intrusion scores of 11.9 and IES avoidance of 11.1, where as in our study IES intrusion in MTOP was 7.66 and in STOP 6.98, IES avoidance of 13.25 in MTOP and 11.53 in STOP. $^{21}$ In our study HADS anxiety score was 6.24 in MTOP and 4.66 in STOP, HADS depression score of 6.53 in MTOP and 4.80 in STOP, while Anne et al reported HADS anxiety score of 6.6 and depression score of 3.9. ${ }^{21}$ Lena $\mathrm{C}$ et al reported surgical abortion IES intrusion and anxiety scores to be significantly higher compared to medical abortion, after four weeks of termination. ${ }^{22}$ Several studies found that medical abortion is associated with high acceptability. This is confirmed in the present study, but acceptability with surgical procedure is even higher. In our study the acceptability in MTOP was $79.6 \%$ and in STOP $95.2 \%$. Rodriguez M et al reported $96 \%$ acceptability with MTOP and 53\% with STOP, Woldetsadik, et al $83.3 \%$ with medical abortion and $77.4 \%$ with MVA Oleg et al reported $29 \%$ women opted for medical abortion and $71 \%$ for STOP with pregnancy less than 7 weeks and $78.3 \%$ of women in 
MTOP and $84.1 \%$ in STOP would choose the method again next time. ${ }^{19,20,23}$

\section{CONCLUSION}

Medical abortion is a good alternative, but no sedation can be given for pain; safe below 8 weeks of last menstrual period, but there is more insecurity, more questions and more complaints than with surgical abortion.

There are several limitations in our study, as this is a single - center observational study of limited members. There are many unmeasured cultural factors and social support during admission, undergoing abortion or post discharge for long term abortion complications. With either of the two methods, significant difference in post abortion emotional state or satisfaction was found. The surgical procedure with MVA under local anesthesia offers a combination of desirable factors, including a single appointment, shorter waiting time, no sight of fetus, less pain and avoidance of the side effects of general anesthesia. In India, where abortion is simultaneously a highly prevalent and yet highly stigmatized procedure, and where there remains widespread misinformation, poor access to services and broad variability in abortion counseling practices, such studies should be done on large scale reaching the unreached.

This study showed that surgical MVA had higher acceptability compared to MTOP and the choice was made mainly because it is a single-visit, complete procedure with less waiting, and avoiding guilt. Both the methods are accepted well and most women are satisfied. Further larger studies are needed as Indian women are more reserved, sensitive, with strong social stigma, cultural beliefs, guilt and fear of resentment, so that they can be given preference to choose a method.

\section{ACKNOWLEDGMENTS}

The authors would like to thank Dr. A Sreenivasa Rao, retired deputy civil surgeon, Family Planning Department, Government Maternity Hospital, Petlaburz, Hyderabad, Telangana India. At present working in PHSI. I also thank Population Health Services of India (PHSI) for supporting to conduct the study.

Funding: No funding sources

Conflict of interest: None declared

Ethical approval: The study was approved by the Institutional Ethics Committee

\section{REFERENCES}

1. Bruyn MD. The acceptability and accessibility of safe abortion: a literature review. Knowledge. hivos; 2015. Available at https://www.researchgate.net/publication/274082829
_The_acceptability_and_accessibility_of_safe_aborti on_A_literature_review.

2. Guttamacher institute and WHO. facts on induced abortion world-wide. Fact Sheet. Geneva, WHO, 2012. Available at https://www.guttmacher.org/factsheet/facts-induced-abortion-worldwide.

3. Kulier R, Kapp N, Gülmezoglu AM, Hofmeyr GJ, Cheng L, Campana A. Medical methods for first trimester abortion. Cochrane database syst. Rev., Chichester, UK: John Wiley and Sons, Ltd; 2011;9(11):CD002855

4. Winikoff B, Dzuba IG, Creinin MD, Crowden WA, Goldberg AB, Gonzales J, et al. Two distinct oral routes of misoprostol in mifepristone medical abortion. Obstet Gynecol. 2008;112(6):1303-10.

5. Von Hertzen H, Huong NTM, Piaggio G, Bayalag M, Cabezas E, Fang AH, et al. Misoprostol dose and route after mifepristone for early medical abortion: a randomised controlled noninferiority trial. BJOG An Int J Obstet Gynaecol. 2010;117(10):1186-96.

6. Creinin MD, Grossman DA. Society of Family Planning. American college of obstetricians and gynaecologists. Practice Bulletin No. 143: medical management of first-trimester abortion. Obstet Gynecol. 2014;123(3):676-92.

7. Chai J, Wong CYG, Ho PC. A randomized clinical trial comparing the short-term side effects of sublingual and buccal routes of misoprostol administration for medical abortions up to 63 days gestation. Contraception. 2013;87(4):480-5.

8. Raymond EG, Shannon C, Weaver MA, Winikoff B. First-trimester medical abortion with mifepristone $200 \mathrm{mg}$ and misoprostol: a systematic review. Contraception. 2013;87(1):26-37.

9. World Health Organisation (WHO). Safe abortion: Technical and policy guidance for health systems. second edi. Geneva, WHO; 2003. Avaialble at http://apps.who.int/iris/bitstream/10665/70914/1/978 9241548434_eng.pdf3.

10. Guerrero JM, Castaño PM, Schmidt EO, Rosario L, Westhoff CL. Music as an auxiliary analgesic during first trimester surgical abortion: a randomized controlled trial. Contraception. 2012;86(2):157-62.

11. Borgatta L, Kattan DR, Stubblefield PG. Surgical techniques for first-trimester abortion. Glob Libr Women's Med. [ISSN:1756-2228(tel:17562228)];2012. Available at http://www.glowm.com/section_view/heading/Surgi cal\%20Techniques $\% 20$ for $\% 20$ FirstTrimester\%20Abortion/item/439.

12. Ware JE, Hays RD. Methods for measuring patient satisfaction with specific medical encounters. Med Care. 1988;26(4):393-402.

13. Henshaw RC, Naji SA, Russell IT, Templeton AA. Comparison of medical abortion with surgical vacuum aspiration: Women's preferences and acceptability of treatment. BMJ 1993;307:714-7.

14. Rosén AS, Nystedt L, Bygdeman M, Lundström V. Acceptability of a nonsurgical method to terminate 
very early pregnancy in comparison to vacuum aspiration. Contraception. 1979;19(2):107-17.

15. Horowitz M, Wilner N, Alvarez W. Impact of event scale: a measure of subjective stress. Psychosom Med. 1979;41:209-18.

16. Zigmond AS, Snaith RP. The hospital anxiety and depression scale. Acta Psychiatr Scand. 1983;67(6):361-70.

17. Rausch M, Lorch S, Chung K, Frederick M, Zhang J, Barnhart K. A cost-effectiveness analysis of surgical versus medical management of early pregnancy loss. Fertil Steril. 2012;97(2):355-60.

18. Wu JP, Godfrey EM, Prine L, Andersen KL, MacNaughton H, Gold M. Women's satisfaction with abortion care in academic family medicine centres. Fam Med. 2015;47(2):98-106.

19. Woldetsadik MA, Sendekie TY, White MT, Zegeye DT. Client preferences and acceptability for medical abortion and MVA as early pregnancy termination method in Northwest Ethiopia. Reprod Health. 2011;8:19.

20. Rodriguez M, Seuc A, Kapp N, von Hertzen H, Huong N, Wojdyla D, et al. Acceptability of misoprostol-only medical termination of pregnancy compared with vacuum aspiration: an international, multicentre trial. BJOG An Int J Obstet Gynaecol. 2012;119(7):817-23.

21. Broen A, Moum T, Bødtker A, Ekeberg $\varnothing$. The Course of mental health after miscarriage and induced abortion: a longitudinal, five year follow-up study. BMC Med. 2005;3:18.

22. Crandell L. Psychological outcomes of medical versus surgical elective first trimester abortion. Nurs Womens Health. 2012;16:296-307.

23. Loeber OE. Motivation and satisfaction with early medical versus surgical abortion in the Netherlands. Reprod Health Matters. 2010;18:145-53.

Cite this article as: Akkenapally PL, Kamineni V. Medical versus surgical termination of early pregnancy: satisfaction with care, emotional impact and acceptability of the procedure. Int J Reprod Contracept Obstet Gynecol 2016;5:3158-66. 